\title{
EVIDENCE-BASED GUIDELINE: NEUROMUSCULAR ULTRASOUND FOR THE DIAGNOSIS OF CARPAL TUNNEL SYNDROME
}

\author{
MICHAEL S. CARTWRIGHT, MD, ${ }^{1}$ LISA D. HOBSON-WEBB, MD, ${ }^{2}$ ANDREA J. BOON, MD, ${ }^{3,4}$ KATHARINE E. ALTER, MD, ${ }^{5,6}$ \\ CHRISTOPHER H. HUNT, MD, ${ }^{7}$ VICTOR H. FLORES, MD, ${ }^{8}$ ROBERT A. WERNER, MD, ${ }^{9}$ STEVEN J. SHOOK, MD, ${ }^{10}$ \\ T. DARRELL THOMAS, MD, ${ }^{11}$ SCOTT J. PRIMACK, DO, ${ }^{12}$ and FRANCIS O. WALKER, MD ${ }^{1}$ \\ ${ }^{1}$ Department of Neurology, Wake Forest School of Medicine, Winston-Salem, North Carolina, USA \\ ${ }^{2}$ Department of Medicine, Division of Neurology, Duke University, Durham, North Carolina, USA \\ ${ }^{3}$ Department of Physical Medicine and Rehabilitation, Mayo Clinic, Rochester, Minnesota, USA \\ ${ }^{4}$ Department of Neurology, Mayo Clinic, Rochester, Minnesota, USA \\ ${ }^{5}$ Rehabilitation Medicine Department, National Institutes of Health, Bethesda, Maryland, USA \\ ${ }^{6}$ Mount Washington Pediatric Hospital, Baltimore, Maryland, USA \\ ${ }^{7}$ Department of Radiology, Mayo Clinic, Rochester, Minnesota, USA \\ ${ }^{8}$ Physical Medicine Associates, Arlington, Texas, USA \\ ${ }^{9}$ University of Michigan Health System, Ann Arbor, Michigan, USA \\ ${ }^{10}$ Neuromuscular Center, Cleveland Clinic, Cleveland, Ohio, USA \\ ${ }^{11}$ Knoxville Neurology Specialists, Knoxville, Tennessee, USA \\ ${ }^{12}$ Colorado Rehabilitation and Occupational Medicine, Aurora, Colorado, USA \\ Accepted 12 March 2012
}

ABSTRACT: Introduction: The purpose of this study was to develop an evidence-based guideline for the use of neuromuscular ultrasound in the diagnosis of carpal tunnel syndrome (CTS). Methods: Two questions were asked: (1) What is the accuracy of median nerve cross-sectional area enlargement as measured with ultrasound for the diagnosis of CTS? (2) What added value, if any, does neuromuscular ultrasound provide over electrodiagnostic studies alone for the diagnosis of CTS? A systematic review was performed, and studies were classified according to American Academy of Neurology criteria for rating articles of diagnostic accuracy (question 1) and for screening articles (question 2). Results: Neuromuscular ultrasound measurement of median nerve cross-sectional area at the wrist is accurate and may be offered as a diagnostic test for CTS (Level A). Neuromuscular ultrasound probably adds value to electrodiagnostic studies when diagnosing CTS and should be considered in screening for structural abnormalities at the wrist in those with CTS (Level B).

Muscle Nerve 46: 287-293, 2012

Carpal tunnel syndrome (CTS) is a combination of signs and symptoms resulting from mononeuropathy of the median nerve as it passes through the rigid carpal tunnel in the wrist. ${ }^{1}$ It is a common condition that affects $2.7 \%$ of the general population and results in health-care costs exceeding $\$ 500$ million annually in the USA.,3 CTS is typically diagnosed by history and physical examination, and electrodiagnostic studies (nerve conduction studies and

Abbreviations: AAN, American Academy of Neurology; AANEM, American Association of Neuromuscular and Electrodiagnostic Medicine; CTS, carpal tunnel syndrome; NCS, nerve conduction studies

Key words: carpal tunnel syndrome; median nerve; mononeuropathy; nerve conduction studies; ultrasound

Disclosures: M.S.C. receives funding from the NIH/NINDS for neuromuscular ultrasound research and royalties from Elsevier for sales of the textbook Neuromuscular Ultrasound. F.O.W. receives royalties from Elsevier for sales of the Neuromuscular Ultrasound.

Approved by the AANEM Board of Directors on January 23, 2012. Correspondence to: C. French, AANEM, 2621 Superior Drive NW, Rochester, MN 55901; e-mail: cfrench@aanen.org

(C) 2012 American Association of Neuromuscular and Electrodiagnostic Medicine. Published online 20 March 2012 in Wiley Online Library (wileyonlinelibrary.com). DOI 10.1002/mus.23389

AAEM Practice Topic sometimes electromyography) are used to confirm the presence of a median mononeuropathy. Electrodiagnostic studies have limitations; they are uncomfortable and do not directly assess the anatomy of the median nerve and its surrounding structures.

Over the past 20 years, neuromuscular ultrasound has been introduced into electrodiagnostic laboratories as a complement to nerve conduction studies and electromyography for the diagnosis of a variety of nerve and muscle conditions. ${ }^{4}$ CTS is the condition most commonly studied with neuromuscular ultrasound, and individuals with CTS have displayed ultrasonographic evidence of focal enlargement of the median nerve at the wrist. ${ }^{5}$ In addition, neuromuscular ultrasound can identify causes of median mononeuropathy at the wrist and structural anomalies that could not be detected with electrodiagnostic studies alone, such as compressive cysts, tumors, and vessels. ${ }^{5}$

This evidence-based guideline was designed to address 2 critical questions regarding the use of neuromuscular ultrasound for the diagnosis of CTS. First, what is the accuracy of median nerve cross-sectional area enlargement, as measured with ultrasound, for the diagnosis of CTS? Second, what added value, if any, does neuromuscular ultrasound provide over electrodiagnostic studies alone for the diagnosis of CTS?

\section{DESCRIPTION OF THE ANALYTIC PROCESS}

The American Association of Neuromuscular and Electrodiagnostic Medicine (AANEM) convened an expert panel of physicians specializing in neurology, physical medicine and rehabilitation, and radiology, selected to represent a broad range of expertise related to neuromuscular ultrasound and CTS. Some panel participants reported using 
neuromuscular ultrasound frequently for clinical and research purposes, and others reported never using the technology. All panel participants had expertise in the clinical and electrodiagnostic assessment of CTS.

In May 2011, PubMed was used to search Medline to identify all potential abstracts. The search terms "carpal tunnel syndrome $O R$ median nerve $O R$ median neuropathy" were combined with the terms "ultrasound $O R$ ultrasonography $O R$ sonogram OR sonography." This produced 724 articles from 1990 to May 2011. This was narrowed to 641 articles by including "English-only" and "humanonly" studies. The titles of those articles were reviewed for relevance, which yielded 240 articles, and each abstract was then reviewed by at least 2 investigators. This resulted in 121 articles for full manuscript review. After each article was reviewed in its entirety by 2 investigators, 67 were identified as relevant for this guideline. In order to be considered relevant, the article had to describe the use of ultrasound to image the wrist in individuals suspected of having CTS.

The 67 relevant articles were rated by at least 2 investigators according to criteria set by the American Academy of Neurology (AAN). ${ }^{6}$ Articles pertaining to the accuracy of median nerve cross-sectional area measurements for the diagnosis of CTS (45 articles) were assessed using the AAN criteria for rating an article on diagnostic accuracy, and articles pertaining to neuromuscular ultrasound as a screening tool to identify anatomic explanations for CTS were assessed using AAN criteria for rating a screening article (23 articles). One article was assessed for both diagnostic accuracy and as a screening article. Both rating systems are included in the Appendices.

Studies with the highest levels of evidence (Class I and II) are discussed in the text and summarized in the evidence tables. At each step in the process, disagreements were arbitrated by a third investigator.

\section{ANALYSIS OF THE EVIDENCE}

Accuracy of Neuromuscular Ultrasound. Forty-five relevant articles pertaining to the accuracy of neuromuscular ultrasound in the diagnosis of CTS were identified. Four were graded as Class I and 2 as Class II. Of the 27 that were Class III, 18 received this rating because they had spectrum bias (in all cases healthy volunteers served as the control group); 6 received this rating because the ultrasonographer was not blinded to clinical or other diagnostic information; and 3 had both spectrum bias and lack of blinding. ${ }^{7-33}$ Spectrum bias occurs when cases and controls are potentially at opposite ends of the disease spectrum, which may artificially enhance the diagnostic accuracy of a test. For example, the articles with spectrum bias reviewed in this study used healthy volunteers as controls rather than a control population more representative of individuals referred for possible CTS in a typical clinical practice. If not explicitly stated in the article that blinding of the ultrasonographer occurred, the corresponding author was e-mailed to clarify this issue, and if no response was received it was categorized as having not been blinded. In general, the Class III articles demonstrated high diagnostic accuracy of ultrasound for the diagnosis of CTS, similar to the Class I and II articles. Of the 12 articles graded as Class IV, 8 received this rating because they did not report enough measures of diagnostic accuracy (sensitivity and specificity, or a likelihood ratio) and 4 because the control group selection was not acceptable. ${ }^{34-45}$ In all 4 cases in which the control group selection was unacceptable, the control group included individuals with symptoms consistent with CTS but normal nerve conduction studies. Although it is important to study individuals with this type of conflicting clinical data (incongruent symptoms and nerve conduction studies), it is the authors' opinion that it is problematic to use such individuals as a control group when assessing the accuracy of a diagnostic test.

Four articles were identified that met Class I level of evidence (Table 1), meaning that the studies were prospective (cohort studies), were blinded, were free of spectrum bias, used appropriate reference standards, and included measures of diagnostic accuracy. ${ }^{46-49}$ Three of the studies defined individuals as having CTS if they had both consistent clinical symptoms and abnormal nerve conduction studies, whereas Altinok et al. defined CTS as those with a consistent clinical presentation and improvement in symptoms after 3 months of non-surgical treatment. Three studies used wrists contralateral to the wrist with CTS as the controls (as long as the participant was asymptomatic on that side and the nerve conduction studies were normal on that side), ${ }^{46,47}$ and Altinok et al. recruited controls from outpatients presenting to the same clinic for causes unrelated to CTS. The presence of different case definitions for CTS is not problematic. In fact, in a condition such as CTS, in which the "gold standard" for diagnosis is debated, it is beneficial in evidence-based guidelines to have studies in which the reference standards for diagnosis were established using different methods. Similarly, it is beneficial to have different control groups, and the authors thought the 2 different control groups (contralateral unaffected hands and individuals referred to the clinic for non-CTS indications) were clinically appropriate 
Table 1. Class I level of evidence studies ${ }^{\star}$ of the accuracy of neuromuscular ultrasound for the diagnosis of carpal tunnel syndrome.

\begin{tabular}{|c|c|c|c|c|c|c|c|c|}
\hline Year & First author & Reference standard & $\begin{array}{l}\text { Number } \\
\text { with CTS }\end{array}$ & $\begin{array}{c}\text { Number } \\
\text { without CTS }\end{array}$ & Sensitivity & Specificity & Accuracy & Area cut-off \\
\hline 2004 & T. Altinok & $\begin{array}{l}\text { Clinical + improvement } \\
\text { and NCS }\end{array}$ & 40 & 40 & $65.0 \%$ & $92.5 \%$ & $78.9 \%$ & $9 \mathrm{~mm}^{2}$ \\
\hline 2004 & S.M. Wong & Clinical + NCS & 64 & 33 & $82.8 \%$ & $72.7 \%$ & $79.3 \%$ & $10 \mathrm{~mm}^{2}$ \\
\hline 2005 & H.-R. Ziswiler & Clinical + NCS & 78 & 23 & $82.0 \%$ & $87.0 \%$ & $83.4 \%$ & $10 \mathrm{~mm}^{2}$ \\
\hline 2010 & A. Mohammadi & Clinical + NCS & 132 & 32 & $97.0 \%$ & $98.0 \%$ & $97.2 \%$ & $8.5 \mathrm{~mm}^{2}$ \\
\hline
\end{tabular}

NA, not available (data presented in the article did not include this value or permit calculation of this value); NCS, nerve conduction studies.

*To meet Class I level of evidence these studies are prospective, are blinded, are free of spectrum bias, have appropriate reference standards, and include measures of diagnostic accuracy.

and minimized spectrum bias. The use of contralateral unaffected wrists also raised the question of whether there was statistical independence between the control wrists and the wrists with CTS. This cannot be definitively answered without the original data. However, if they were not independent, that would make the control and affected wrists more similar, which would likely result in an underestimation of the diagnostic accuracy of the test.

The four Class I studies used slightly different median nerve cross-sectional area cut-offs to diagnose CTS (ranging from 8.5 to $10 \mathrm{~mm}^{2}$ ), and all studies used the direct tracing method to measure median nerve area. Ziswiler et al. measured the median nerve at the site of maximal enlargement at the wrist, and the other 3 studies measured the nerve at, or just proximal to, the level of the pisiform bone. Our guideline development panel considered studies with diagnostic accuracy $>70 \%$ to be acceptable and supportive of neuromuscular ultrasound for the diagnosis of CTS (accuracy = sensitivity $\times$ prevalence + specificity $\times(1-$ prevalence)). The sensitivity of median nerve cross-sectional area for the diagnosis of CTS ranged from $65 \%$ to $97 \%$, specificity from $72.7 \%$ to $98 \%$, and accuracy from $79 \%$ to $97 \%$. Interestingly, Altinok et al. also analyzed their data using nerve conduction studies in addition to clinical diagnosis, and this more strict case definition of CTS resulted in an increase in the sensitivity of neuromuscular ultrasound from $65 \%$ to $100 \%$.

Two Class II articles were identified (Table 2), and they met the same criteria as the Class I articles, except they involved retrospective data collection (case-control studies). ${ }^{50,51}$ Nakamichi and Tachibana used only clinical criteria to classify participants as CTS or controls, and the control subjects were recruited from a health fair. The median nerve cross-sectional area was calculated by tracing the nerve at 3 sites within the carpal tunnel and taking the mean of those measurements, with 12 $\mathrm{mm}^{2}$ selected as the cut-off for the diagnosis of CTS. The study by Klauser et al. is unique among the 6 Class I and II articles in that it only examined those with bifid median nerves within the carpal tunnel. The area of each portion of the nerve was traced and then added together, and a single cut-off of $12 \mathrm{~mm}^{2}$ was used. They also reported improved accuracy when the difference between the median nerve area measured at the wrist and proximal forearm was calculated, with a difference of $4 \mathrm{~mm}^{2}$ or greater used to diagnose CTS.

Conclusion. Based on consistent Class I and Class II evidence, neuromuscular ultrasound measurement of median nerve cross-sectional area at the wrist is established as accurate for the diagnosis of CTS.

Recommendation: If available, neuromuscular ultrasound measurement of median nerve crosssectional area at the wrist may be offered as an accurate diagnostic test for CTS (Level A).

Clinical Context. As is the case with all ultrasonographic imaging, neuromuscular ultrasound of the median nerve at the wrist should be performed and interpreted by clinicians experienced with the technique. Scanning protocols and reference values for median nerve cross-sectional area at the

Table 2. Class II level of evidence studies* of the accuracy of neuromuscular ultrasound for the diagnosis of carpal tunnel syndrome.

\begin{tabular}{|c|c|c|c|c|c|c|c|c|}
\hline Year & First author & $\begin{array}{c}\text { Reference } \\
\text { standard }\end{array}$ & $\begin{array}{l}\text { Number } \\
\text { with CTS }\end{array}$ & $\begin{array}{c}\text { Number } \\
\text { without CTS }\end{array}$ & Sensitivity & Specificity & Accuracy & Area cut-off \\
\hline 2002 & K. Nakamichi & Clinical & 414 & 408 & $67.0 \%$ & $97.0 \%$ & $82.0 \%$ & $12 \mathrm{~mm}^{2}$ \\
\hline & & & & & $92.5 \%$ & $96.4 \%$ & $93.9 \%$ & $\Delta 4 \mathrm{~mm}^{2 \ddagger}$ \\
\hline
\end{tabular}

*To meet Class I/ level of evidence these studies are retrospective, are blinded, are free of spectrum bias, and include measures of diagnostic accuracy.

this study only evaluated those with bifid median nerves.

FThis is the difference in median nerve area at the wrist compared to the forearm. 
Table 3. Class II level of evidence studies* of the added value of neuromuscular ultrasound in the diagnosis of carpal tunnel syndrome.

\begin{tabular}{lccc}
\hline Year & First author & $\begin{array}{c}\text { Number } \\
\text { with CTS }\end{array}$ & \multicolumn{1}{c}{ Percentage and type of abnormal structures } \\
\hline 1993 & K. Nakamichi & 20 & $25 \%$ with unilateral CTS (by clinical and NCS criteria) have occult \\
& & ganglia in the carpal tunnel \\
2000 & E. lannicelli & 294 & $2 \%$ with CTS have a bifid median nerve \\
2008 & 320 & $13 \%$ with CTS have a bifid median nerve \\
2011 & 35 & $6 \%$ with CTS have a persistent median artery \\
& I. Bayrak & & $17 \%$ with CTS have a finding that changes therapeutic approach \\
& & $9 \%$ have a bifid median nerve
\end{tabular}

*To meet Class II level of evidence these studies draw from a statistical and non-referral clinic-based sample of patients, evaluate all CTS patients prior to surgery, and conduct neuromuscular ultrasound on all study participants.

wrist should be established by each laboratory prior to using neuromuscular ultrasound for the diagnosis of CTS.

Added Value of Neuromuscular Ultrasound. Twentythree articles were identified that potentially demonstrated the added value of neuromuscular ultrasound as a diagnostic tool when used in combination with electrodiagnostic studies. Four were graded as Class II (Table 3), and the rest were classified as Class IV (all of these were case reports and case series). None were graded as Class I, because no studies drew from a population-based sample of patients. None were Class III, because all the studies that were not case reports or case series met Class II criteria.

The 4 articles that met Class II criteria described studies that drew from a statistical and non-referral clinic-based sample of patients, evaluated all CTS patients prior to surgery, and included neuromuscular ultrasound on all study participants. ${ }^{7,52-54}$ Three of these articles described the detection of bifid median nerves at the wrist, and $2-13 \%$ of those with CTS had a bifid nerve. ${ }^{7,53,54}$ Two studies described the detection of persistent median arteries, which occurred in 9$13 \%$ of those with CTS., ${ }^{7,54}$ The study by Padua et al. also described the detection of tenosynovitis $(6 \%)$ and accessory muscles within the wrist (3\%) in those with CTS. The study by Nakamichi and Tachibana was unique in that it assessed the affected wrists in those with unilateral CTS (meaning the contralateral side was normal by clinical and nerve conduction criteria). Neuromuscular ultrasound detected occult ganglia causing median mononeuropathy in $25 \%$ of the CTS-affected wrists in this population.

All 19 of the Class IV articles were case reports or case series in which neuromuscular ultrasound was used to identify abnormal structures causing median mononeuropathy at the wrist. These structures included traumatic neuromas, Schwannomas, lipofibromatous hamartomas, ganglion cysts, thrombosed persistent median arteries, an abscess, and compressive gouty tophus. ${ }^{55-73}$

Conclusion. Based on Class II evidence, neuromuscular ultrasound of the wrist probably adds value to electrodiagnostic studies when assessing CTS as it can detect structural abnormalities.

Recommendation: If available, neuromuscular ultrasound should be considered to screen for structural abnormalities at the wrist in those with CTS (Level B).

Clinical Context. Screening for structural abnormalities at the wrist that cause CTS is likely to be of higher yield in those with atypical CTS. This was demonstrated by Nakamichi and Tachibana, who found a high rate of occult ganglia only in those with unilateral CTS. This is an atypical presentation, as most patients have bilateral CTS (defined by symptoms, nerve conduction studies, or both). ${ }^{52}$ Other atypical presentations of CTS include sudden onset and onset in the setting of trauma. Although ultrasound can identify structural abnormalities, it is possible these abnormalities may not always be the underlying cause of the median mononeuropathy. In addition, the prevalence of such abnormalities in the general population is not known, so the sensitivity and specificity of ultrasound for the identification of these structures cannot be calculated based on currently available data. The wide prevalence range for bifid median nerves (2-13\%) may be secondary to ultrasound device resolution (earlier studies identified fewer bifid nerves), ultrasound technique and site of imaging within the wrist, or patient population. The presence of structures such as persistent median arteries and accessory muscles is clearly of therapeutic interest, as it may alter the choice of interventional approach (either injection or 
surgery). Knowledge of a bifid median nerve and other anatomic variants is also of interest in planning the treatment of CTS, ${ }^{53}$ and identification of such variants prior to invasive intervention can even assist later in the assessment of failed intervention. In addition, the presence of a bifid median nerve may be an independent risk factor for the development of CTS. ${ }^{7}$

\section{CLINICAL CONTEXT SUMMARY FOR ALL EVIDENCE}

A single neuromuscular ultrasound evaluation of the wrist in those with CTS allows for assessment of both median nerve cross-sectional area and the presence of structural abnormalities, and this complements well the information obtained during an electrodiagnostic study (which is the gold standard for diagnosis of CTS). Some variability exists in the devices, scanning protocols, and reference ranges for the diagnosis of CTS when using neuromuscular ultrasound, but this is to be expected. As a comparison, similar variability exists in electrodiagnostic techniques. It is anticipated that with continued experience with neuromuscular ultrasound techniques, more uniformity will occur as consensus develops regarding optimal use of the technology. It should also be noted that many studies have proposed other neuromuscular ultrasound parameters that can be used to assist in the diagnosis of CTS, but these were not assessed in this guideline. These include median nerve flattening ratios; measures of median nerve mobility, echogenicity, and vascularity; and measures of flexor retinaculum bowing.

\section{RECOMMENDATIONS FOR FUTURE RESEARCH}

1 A standardized protocol for using neuromuscular ultrasound in the diagnosis of CTS should be developed. This should include definition of the optimal site of median nerve cross-sectional area measurement, standardization of nerve outlining technique, and further refinement of reference values.

2 Further research and evidence-based guidelines should assess the usefulness of other neuromuscular ultrasound parameters for the diagnosis of CTS, such as median nerve flattening, mobility, echogenicity, vascularity, and bowing of the flexor retinaculum.

3 Large population-based studies that enroll consecutive patients with CTS should be performed to assess for all structural abnormalities that may be causative or change therapeutic approach, which will help further determine the added benefit of neuromuscular ultrasound in the diagnosis of CTS.

4 Finally, large studies should be performed to determine whether neuromuscular ultrasound changes treatment strategies and outcomes in those with CTS when compared with those in which CTS is established using only electrodiag- nostic studies. This type of study should also allow for cost-benefit analyses of neuromuscular ultrasound in the diagnosis of CTS.

\section{DISCLAIMER}

This statement has been provided as an educational service of the AANEM. It is based on an assessment of current scientific and clinical information. It is not intended to include all possible proper methods of care of a particular neurological problem or all legitimate criteria for choosing to use a specific procedure. Neither is it intended to exclude any reasonable alternative methodology. The AANEM recognizes that specific patient care decisions are the prerogative of the patient and the physician caring for the patient, based on all of the circumstances involved. The clinical context section is made available in order to place the evidence-based guidelines into perspective with current practice habits and challenges. No formal practice recommendation should be inferred.

The authors thank Gary Gronseth, MD, for his gracious assistance and shared expertise regarding the grading of evidence, which was critical for the creation of this evidence-based guideline.

\section{APPENDIX 1: AAN CLASSIFICATION OF THE EVIDENCE FOR RATING OF A DIAGNOSTIC ARTICLE ${ }^{6}$}

Class I: A cohort study with prospective data collection of a broad spectrum of persons with the suspected condition, using an acceptable reference standard for case definition. The diagnostic test is objective or performed and interpreted without knowledge of the patient's clinical status. Study results allow calculation of measures of diagnostic accuracy.

Class II: A case-control study of a broad spectrum of persons with the condition established by an acceptable reference standard compared with a broad spectrum of controls, or a cohort study with a broad spectrum of persons with the suspected condition where the data were collected retrospectively. The diagnostic test is objective or performed and interpreted without knowledge of disease status. Study results allow calculation of measures of diagnostic accuracy.

Class III: A case-control study or cohort study where either persons with the condition or controls are of a narrow spectrum. The condition is established by an acceptable reference standard. The reference standard and diagnostic test are objective or performed and interpreted by different observers. Study results allow calculation of measures of diagnostic accuracy.

Class IV: Studies not meeting Class I, II, or III criteria, including consensus, expert opinion, or a case report. 


\section{APPENDIX 2: AAN CLASSIFICATION OF THE EVIDENCE} FOR RATING OF A SCREENING ARTICLE6

Class I: A statistical, population-based sample of patients studied at a uniform point in time (usually early) during the course of the condition. All patients undergo the intervention of interest. The outcome, if not objective, is determined in an evaluation that is masked to the patients' clinical presentations.

Class II: A statistical, non-referral clinic-based sample of patients studied at a uniform point in time (usually early) during the course of the condition. Most patients undergo the intervention of interest. The outcome, if not objective, is determined in an evaluation that is masked to the patients' clinical presentations.

Class III: A sample of patients studied during the course of the condition. Some patients undergo the intervention of interest. The outcome, if not objective, is determined in an evaluation by someone other than the treating physician.

Class IV: Studies not meeting Class I, II, or III criteria, including consensus, expert opinion, or a case report.

\section{APPENDIX 3: CLASSIFICATION OF RECOMMENDATIONS}

The four possible recommendation classifications include:

- $\mathrm{A}=$ Established as effective, ineffective or harmful (or established as useful/predictive or not useful/predictive) for the given condition in specified population. (Level A rating requires at least 2 consistent Class I studies.) [In exceptional cases, 1 convincing Class I study may suffice for an "A" recommendation if: (1) all criteria are met; and (2) the magnitude of effect is large (relative rate improved outcome $>5$ and the lower limit of the confidence interval is $>2$.]

- $\mathrm{B}=$ Probably effective, ineffective, or harmful (or probably useful/predictive or not useful/predictive) for the given condition in the specified population. (Level B rating requires at least 1 Class I study or 2 consistent Class II studies.)

- $\mathrm{C}=$ Possibly effective, ineffective, or harmful (or possibly useful/predictive or not useful/predictive) for the given condition in the specified population. (Level $\mathrm{C}$ rating requires at least 1 Class II study or 2 consistent Class III studies.)

- $\mathrm{U}=$ Data inadequate or conflicting; given current knowledge, treatment (test, predictor) is unproven.

\section{REFERENCES}

1. Gelberman RH, Hergenroeder PT, Hargens AR, Lundborg GN, Akeson WH. The carpal tunnel syndrome. A study of carpal canal pressures. J Bone Joint Surg Am 1981;63:380-383.
2. Atroshi I, Gummesson C, Johnsson R, Ornstein E, Ranstam J, Rosen I. Prevalence of carpal tunnel syndrome in a general population. JAMA 1999;282:153-158.

3. Stevens JC, Sun S, Beard CM, O'Fallon WM, Kurland LT. Carpal tunnel syndrome in Rochester, Minnesota, 1961 to 1980. Neurology 1988;38:134-138.

4. Walker FO, Cartwright MS, Wiesler ER, Caress J. Ultrasound of nerve and muscle. Clin Neurophysiol 2004;115:495-507.

5. Beekman R, Visser LH. Sonography in the diagnosis of carpal tunnel syndrome: a critical review of the literature. Muscle Nerve 2003;27 26-33.

6. American Academy of Neurology. Clinical practice guideline process manual. St. Paul, MN: American Academy of Neurology; 2011.

7. Bayrak IK, Bayrak AO, Kale M, Turker H, Diren B. Bifid median nerve in patients with carpal tunnel syndrome. J Ultrasound Med 2008;27:1129-1136.

8. Duncan I, Sullivan P, Lomas F. Sonography in the diagnosis of carpal tunnel syndrome. AJR Am J Roentgenol 1999;173:681-684.

9. El Miedany YM, Aty SA, Ashour S. Ultrasonography versus nerve conduction study in patients with carpal tunnel syndrome: substantive or complementary tests? Rheumatology (Oxford) 2004;43:887-895.

10. Iannicelli E, Almberger M, Chianta GA, Salvini V, Rossi G, Monacell $\mathrm{G}$, et al. High resolution ultrasonography in the diagnosis of the carpal tunnel syndrome. Radiol Med 2005;110:623-629.

11. Kele H, Verheggen R, Bittermann HJ, Reimers CD. The potential value of ultrasonography in the evaluation of carpal tunnel syndrome. Neurology 2003;61:389-391.

12. Kotevoglu N, Gulbahce-Saglam S. Ultrasound imaging in the diagnosis of carpal tunnel syndrome and its relevance to clinical evaluation. Joint Bone Spine 2005;72:142-145.

13. Koyuncuoglu HR, Kutluhan S, Yesildag A, Oyar O, Guler K, Ozden A. The value of ultrasonographic measurement in carpal tunnel syndrome in patients with negative electrodiagnostic tests. Eur J Radio 2005;56:365-369.

14. Sarria L, Cabada T, Cozcolluela R, Martinez-Berganza T, Garcia S Carpal tunnel syndrome: usefulness of sonography. Eur Radiol 2000; 10:1920-1925.

15. Wiesler ER, Chloros GD, Cartwright MS, Smith BP, Rushing J, Walker FO. The use of diagnostic ultrasound in carpal tunnel syndrome. J Hand Surg Am 2006;31:726-732.

16. Wong SM, Griffith JF, Hui AC, Tang A, Wong KS. Discriminatory sonographic criteria for the diagnosis of carpal tunnel syndrome. Arthritis Rheum 2002;46:1914-1921.

17. Yesildag A, Kutluhan S, Sengul N, Koyuncuoglu HR, Oyar O, Guler $\mathrm{K}$, et al. The role of ultrasonographic measurements of the median nerve in the diagnosis of carpal tunnel syndrome. Clin Radiol 2004; 59:910-915

18. Akcar N, Ozkan S, Mehmetoglu O, Calisir C, Adapinar B. Value of power Doppler and gray-scale US in the diagnosis of carpal tunnel syndrome: contribution of cross-sectional area just before the tunnel inlet as compared with the cross-sectional area at the tunnel. Korean J Radiol 2010;11:632-639.

19. Ashraf AR, Jali R, Moghtaderi AR, Yazdani AH. The diagnostic value of ultrasonography in patients with electrophysiologicaly confirmed carpal tunnel syndrome. Electromyogr Clin Neurophysiol 2009;49: $3-8$

20. Ghasemi-Esfe AR, Khalilzadeh O, Mazloumi M, Vaziri-Bozorg SM, Niri SG, Kahnouji H, et al. Combination of high-resolution and color Doppler ultrasound in diagnosis of carpal tunnel syndrome. Acta Radiol 2011;52:191-197.

21. Kaymak B, Ozcakar L, Cetin A, Candan CM, Akinci A, Hascelik Z. A comparison of the benefits of sonography and electrophysiologic measurements as predictors of symptom severity and functional status in patients with carpal tunnel syndrome. Arch Phys Med Rehabil 2008;89:743-748.

22. Keles I, Karagulle Kendi AT, Aydin G, Zog SG, Orkun S. Diagnostic precision of ultrasonography in patients with carpal tunnel syndrome. Am J Phys Med Rehabil 2005;84:443-450.

23. Klauser AS, Halpern EJ, De ZT, Feuchtner GM, Arora R, Gruber J, et al. Carpal tunnel syndrome assessment with US: value of additional cross-sectional area measurements of the median nerve in patients versus healthy volunteers. Radiology 2009;250:171-177.

24. Kurca E, Nosal V, Grofik M, Sivak S, Turcanova-Koprusakova M, Kucera P. Single parameter wrist ultrasonography as a first-line screening examination in suspected carpal tunnel syndrome patients. Bratisl Lek Listy 2008;109:177-179.

25. Kwon BC, Jung KI, Baek GH. Comparison of sonography and electrodiagnostic testing in the diagnosis of carpal tunnel syndrome. J Hand Surg Am 2008;33:65-71.

26. Lee D, van Holsbeeck MT, Janevski PK, Ganos DL, Ditmars DM, Darian VB. Diagnosis of carpal tunnel syndrome. Ultrasound versus electromyography. Radiol Clin N Am 1999;37:859-872, x.

27. Leonard L, Rangan A, Doyle G, Taylor G. Carpal tunnel syndromeis high-frequency ultrasound a useful diagnostic tool? J Hand Surg Br 2003;28:77-79 
28. Pastare D, Therimadasamy AK, Lee E, Wilder-Smith EP. Sonography versus nerve conduction studies in patients referred with a clinical diagnosis of carpal tunnel syndrome. J Clin Ultrasound 2009;37:389-393.

29. Pinilla I, Martin-Hervas C, Sordo G, Santiago S. The usefulness of ultrasonography in the diagnosis of carpal tunnel syndrome. J Hand Surg Eur Vol 2008;33:435-439.

30. Sernik RA, Abicalaf CA, Pimentel BF, Braga-Baiak A, Braga L, Cerri GG. Ultrasound features of carpal tunnel syndrome: a prospective case-control study. Skeletal Radiol 2008;37:49-53.

31. Swen WA, Jacobs JW, Bussemaker FE, de Waard JW, Bijlsma JW. Carpal tunnel sonography by the rheumatologist versus nerve conduction study by the neurologist. J Rheumatol 2001;28:62-69.

32. Visser LH, Smidt MH, Lee ML. High-resolution sonography versus EMG in the diagnosis of carpal tunnel syndrome. J Neurol Neurosurg Psychiatry 2008;79:63-67.

33. Wang LY, Leong CP, Huang YC, Hung JW, Cheung SM, Pong YP. Best diagnostic criterion in high-resolution ultrasonography for carpal tunnel syndrome. Chang Gung Med J 2008;31:469-476.

34. Buchberger W, Judmaier W, Birbamer G, Lener M, Schmidauer C. Carpal tunnel syndrome: diagnosis with high-resolution sonography. AJR Am J Roentgenol 1992;159:793-798.

35. Buchberger W, Schon G, Strasser K, Jungwirth W. High-resolution ultrasonography of the carpal tunnel. J Ultrasound Med 1991;10: $531-537$.

36. Hammer HB, Hovden IA, Haavardsholm EA, Kvien TK. Ultrasonography shows increased cross-sectional area of the median nerve in patients with arthritis and carpal tunnel syndrome. Rheumatology (Oxford) 2006;45:584-588.

37. Hobson-Webb LD, Massey JM, Juel VC, Sanders DB. The ultrasonographic wrist-to-forearm median nerve area ratio in carpal tunnel syndrome. Clin Neurophysiol 2008;119:1353-1357.

38. Mallouhi A, Pulzl P, Trieb T, Piza H, Bodner G. Predictors of carpal tunnel syndrome: accuracy of gray-scale and color Doppler sonography. AJR Am J Roentgenol 2006;186:1240-1245.

39. Nakamichi KI, Tachibana S. Enlarged median nerve in idiopathic carpal tunnel syndrome. Muscle Nerve 2000;23:1713-1718.

40. Colak A, Kutlay M, Pekkafali Z, Saracoglu M, Demircan N, Simsek H, et al. Use of sonography in carpal tunnel syndrome surgery. A prospective study. Neurol Med Chir (Tokyo) 2007;47:109-115.

41. Domanasiewicz A, Koszewicz M, Jablecki J. Comparison of the diagnostic value of ultrasonography and neurography in carpal tunnel syndrome. Neurol Neurochir Pol 2009;43:433-438.

42. Mondelli M, Filippou G, Gallo A, Frediani B. Diagnostic utility of ultrasonography versus nerve conduction studies in mild carpal tunnel syndrome. Arthritis Rheum 2008;59:357-366.

43. Moran L, Perez M, Esteban A, Bellon J, Arranz B, del Cerro M. Sonographic measurement of cross-sectional area of the median nerve in the diagnosis of carpal tunnel syndrome: correlation with nerve conduction studies. J Clin Ultrasound 2009;37:125-131.

44. Naranjo A, Ojeda S, Mendoza D, Francisco F, Quevedo JC, Erausquin $\mathrm{C}$. What is the diagnostic value of ultrasonography compared to physical evaluation in patients with idiopathic carpal tunnel syndrome? Clin Exp Rheumatol 2007;25:853-859.

45. Padua L, Pazzaglia C, Caliandro P, Granata G, Foschini M, Briani C, et al. Carpal tunnel syndrome: ultrasound, neurophysiology, clinical and patient-oriented assessment. Clin Neurophysiol 2008;119:2064-2069.

46. Altinok T, Baysal O, Karakas HM, Sigirci A, Alkan A, Kayhan A, et al. Ultrasonographic assessment of mild and moderate idiopathic carpal tunnel syndrome. Clin Radiol 2004;59:916-925.

47. Wong SM, Griffith JF, Hui AC, Lo SK, Fu M, Wong KS. Carpal tunnel syndrome: diagnostic usefulness of sonography. Radiology 2004; 232:93-99.

48. Ziswiler HR, Reichenbach S, Vogelin E, Bachmann LM, Villiger PM, Juni P. Diagnostic value of sonography in patients with suspected carpal tunnel syndrome: a prospective study. Arthritis Rheum 2005;52:304-311.

49. Mohammadi A, Afshar A, Etemadi A, Masoudi S, Baghizadeh A. Diagnostic value of cross-sectional area of median nerve in grading severity of carpal tunnel syndrome. Arch Iran Med 2010;13:516-521.

50. Nakamichi K, Tachibana S. Ultrasonographic measurement of median nerve cross-sectional area in idiopathic carpal tunnel syndrome: diagnostic accuracy. Muscle Nerve 2002;26:798-803.
51. Klauser AS, Halpern EJ, Faschingbauer R, Guerra F, Martinoli C, Gabl MF, et al. Bifid median nerve in carpal tunnel syndrome: assessment with US cross-sectional area measurement. Radiology 2011;259: $808-815$.

52. Nakamichi K, Tachibana S. Unilateral carpal tunnel syndrome and space-occupying lesions. J Hand Surg Br 1993;18:748-749.

53. Iannicelli E, Chianta GA, Salvini V, Almberger M, Monacelli G, Passariello R. Evaluation of bifid median nerve with sonography and MR imaging. J Ultrasound Med 2000;19:481-485.

54. Padua L, Liotta G, Di Pascuale A, Granata G, Pazzaglia C, Caliandro $\mathrm{P}$, et al. Contribution of ultrasound in the assessment of nerve diseases. Eur J Neurol 2012;19:47-54.

55. Bertolotto M, Rosenberg I, Parodi RC, Perrone R, Gentile S, Rollandi GA, et al. Case report: Fibroma of tendon sheath in the distal forearm with associated median nerve neuropathy: US, CT and MR appearances. Clin Radiol 1996;51:370-372.

56. Elsaidi GA, Wiesler ER. Lipofibromatous hamartoma of the median nerve: case presentation of MRI, ultrasound, electrodiagnostic, histologic, and surgical findings. Am J Orthop 2004;33:514-516.

57. Hobson-Webb LD, Walker FO. Traumatic neuroma diagnosed by ultrasonography. Arch Neurol 2004;61:1322-1323.

58. Kato H, Ogino T, Nanbu T, Nakamura K. Compression neuropathy of the motor branch of the median nerve caused by palmar ganglion. J Hand Surg Am 1991;16:751-752.

59. Kele H, Verheggen R, Reimers CD. Carpal tunnel syndrome caused by thrombosis of the median artery: the importance of high-resolution ultrasonography for diagnosis. Case report. J Neurosurg 2002; 97:471-473.

60. Kobayashi N, Koshino T, Nakazawa A, Saito T. Neuropathy of motor branch of median or ulnar nerve induced by midpalm ganglion. J Hand Surg Am 2001;26:474-477.

61. Kuo YL, Yao WJ, Chiu HY. Role of sonography in the preoperative assessment of neurilemmoma. J Clin Ultrasound 2005;33:87-89.

62. Nakamichi K, Tachibana S. Ultrasonography in the diagnosis of carpal tunnel syndrome caused by an occult ganglion. J Hand Surg $\mathrm{Br}$ 1993;18:174-175.

63. Padua L, Aprile I, Pazzaglia C, Frasca G, Caliandro P, Tonali P, et al Contribution of ultrasound in a neurophysiological lab in diagnosing nerve impairment: a one-year systematic assessment. Clin Neurophysiol 2007;118:1410-1416.

64. Anna LG, Di Pasquale A, Lucchetta M, Alberti MA, Padua L. Ultrasound view of a traumatic two-level median nerve lesion. Muscle Nerve 2011;43:767-768.

65. Chen KH, Lee KF, Hsu HC, Huang WC, Hsiao KY, Fang KM. The role of high-resolution ultrasound in the diagnosis of a traumatic neuroma in an injured median nerve. Am J Phys Med Rehabil 2009; 88:771-774.

66. Chen P, Massengill A, Maklad N, Roder E. Nerve territory-oriented macrodactyly: unusual cause of carpal tunnel syndrome. J Ultrasound Med 1996;15:661-664.

67. Declercq H, De Man R, van Herck G, Tanghe W, Lateur L. Case report 814: Fibrolipoma of the median nerve. Skeletal Radiol 1993; 22:610-613.

68. Fumiere E, Dugardeyn C, Roquet ME, Delcour C. US demonstration of a thrombosed persistent median artery in carpal tunnel syndrome. JBR-BTR 2002;85:1-3.

69. Hui AC, Wong SM, Griffith JF. An unusual cause of carpal tunnel syndrome. Int J Clin Pract 2003;57:635-636.

70. Kara M, Erkin G, Malas FU, Kaymak B, Uysal H, Ozcakar L. Carpal tunnel syndrome in two cases of all ulnar hand: a word for nerve's ultrasound. Acta Reumatol Port 2010;35:403-405.

71. Padua L, Pazzaglia C, Insola A, Aprile I, Caliandro P, Rampoldi M, et al. Schwannoma of the median nerve (even outside the wrist) may mimic carpal tunnel syndrome. Neurol Sci 2006;26:430-434.

72. Sucher BM. Carpal tunnel syndrome: ultrasonographic imaging and pathologic mechanisms of median nerve compression. J Am Osteopath Assoc 2009;109:641-647.

73. Therimadasamy A, Peng YP, Putti TC, Wilder-Smith EP. Carpal tunnel syndrome caused by gouty tophus of the flexor tendons of the fingers: sonographic features. J Clin Ultrasound 2011;39: $463-465$. 